\title{
Makna kebahagiaan mahasiswa perantau
}

\author{
Rahmatul Jannah \\ Magister Psikologi, Program Pascasarjana, Universitas Ahmad Dahlan \\ rahmatuljannah288@gmail.com \\ Martha Soraya Putra \\ Magister Psikologi, Program Pascasarjana, Universitas Ahmad Dahlan \\ marthasoraya1@gmail.com \\ Aziz Syamsul Nurudin \\ Magister Psikologi, Program Pascasarjana, Universitas Ahmad Dahlan \\ azizsyamsulnurudin@gmail.com \\ Nina Zulida Situmorang \\ Magister Psikologi, Program Pascasarjana, Universitas Ahmad Dahlan \\ nzsitumorang@gmail.com
}

\begin{abstract}
ABSTRAK
Dewasa awal merupakan periode perubahan individu baik perubahan fisik dan psikologis. Awal mula masa dewasa awal adalah kemandirian ekonomi dan kemandirian dalam membuat keputusan, yang mana hal-hal ini untuk mencapai kebahagiaan dalam hidup, banyak orang bersaing untuk mnenemukan kebahagiaan. Salah satunya adalah siswa perantau yang rela meninggalkan daerah asalnya untuk pendidikan terbaik di Yogyakarta. Karenabarumenjadimahasiswaperantau, mereka akan menghadapi tantangan yang dapat memengaruhi kebahagiaan mereka. Penelitian ini membahas bagaimana memahami makna kebahagiaan pada siswa perantau yang tinggal di kota Yogyakarta. Penelitian ini adalah penelitian kualitatif dengan membahas realisme konstruktif yang membahas data dengan kuesioner terbuka dan FGD. Pemilihan subjek yang insidental didasarkan pada transisi, yang terdiri dari 20 subjek laki-laki dan 40 subjek perempuan. Data dianalisis dengan menggabungkan teks data kategorisasi. Studi ini menghasilkan tiga kategori, termasuk 65,36\% hubungan positif, kebersyukuran 28,10\%, dan kesehatan 6,54\%. Hasil penelitian menunjukkan bahwa makna kebahagiaan siswa perantau adalah gabungan individu yang memiliki hubungan positif, bersyukur atas apa yang dihasilkan, dan juga sehat.
\end{abstract}

Kata Kunci : Bahagia, Dewasa Awal, Mahasiswa Perantau

\begin{abstract}
Early adulthood is periods of change for individual from physical and psychological. The beginning of early adulthood is economic independence and independence in making decisions, which are these things to achieve happiness in life, many people compete to find happiness. One of them is overseas students who are willing to leave their home regions for the best education in Yogyakarta. Because they have just become overseas students, they will successfully challenge those who can influence their happiness. This study discusses how to understand happiness in foreign students who live in the city of Yogyakarta. This research is a qualitative study by discussing constructive realism which discusses data with an open questionnaire and FGD. Selection of subjects based on the transition, which consists of 20 male subjects and 40 female subjects. Data were analyzed by reading the text of categorization data. This study produced three categories, including $65.36 \%$ positive relationships, $28.10 \%$ happiness, and $6.54 \%$ health. The results
\end{abstract}


Jurnal Psikologi Terapan dan Pendidikan

ISSN: $2715-2456$

Vol. 1, No. 1, Mei 2019, pp. 22-29

showed the meaning of the happiness of overseas students was a combination of individuals who had positive relationships, were grateful for what was produced, and were also healthy.

Keywords : Early Childhood, Migrant Students, Happiness

\section{PENDAHULUAN}

Kebahagiaan adalah tujuan setiap individu dan setiap individu memiliki arti tersendiri untuk sebuah kebahagiaan. Menurut Aristoteles (Seligman, 2013) seluruh tindakan yang dilakukanoleh manusia adalah untuk mencapai kebahagiaan, banyak orang berlomba-lomba dalam mencari dan mendapatkan suatu kebahahgiaan. Setiap manusia memaknai kebahagiaan merupakan suatu bentuk pencapaian tujuan hidup yang hakiki. Penduduk Indonesia secara umum sudah dikatakan cukup bahagia jika dilihat dari rata-rata indeks kebahagiaan Indonesia tahun 2017 sebesar 70,69. Khusus di Provinsi DI Yogyakarta indeks kebahagiaan juga cukup tinggi, yaitu sebesar 72,93 (Badan Pusat Statistik, 2017) Dengan tingginya kebahagiaan di kota Yogyakarta seharusnya dapat meingkatkan keberhasilan dan kenyamanan terutama bagi para mahasiswa perantau. Seperti kita ketahui bahwa pendidikan merupakan salah satu hal penting yang harus dimiliki seseorang dalam kehidupannya.

Mahasiswa adalah pelajar ditingkat perguruan tinggi, banyak perguruan tinggi yang tersebar di seluruh Indonesia. Alasan utama orang merantau adalah untuk meraih kesuksesan, yang membutuhkan keberanian agar lebih percaya diri dan mandiri (Chandra, 2010), serta siap menghadapi berbagai perubahan situasi dan lingkungan baru (Purwono, 2011). Fenomena mahasiswa perantau melalui proses peningkatan kualitas pendidikan, serta sebagai wujud usaha membuktikan kualitas diri sebagai orang dewasa yang mandiri dan bertanggung jawab dalam membuat keputusan (Santrock, 2009).

Yogyakarta adalah suatu daerah yang dikenal sebagai kota pelajar oleh karena itu banyak mahasiswa perantau yang rela meninggalkan daerah asalnya untuk mendapatkan pendidikan yang terbaik di Yogyakarta. Senada dengan hal tersebut Hurlock (1999) mengemukakan bahwa untuk mencapai tujuan dari pola sosialisasi dewasa juga dibutuhkan banyak penyesuaian baru, diantaranya yang dialami mahasiswa perantau yaitu ketidakhadiran orang tua dan sistem pertemanan dan komunikasi yang berbeda dengan teman baru serta penyesuaian dengan norma sosialisasi warga setempat (Hutapea,2006). Hal tersebut tentu saja menyebabkan perubahan situasi yang bisa kehidupan yang dapat menghambat pencapaian prestasi mahasiswa perantau.

Ketika memasuki suatu lingkungan yang baru, individu merasakan berbagai masalah terutama yang disebabkan oleh perbedaan bahasa dan perbedaan kebudayaan seperti makanan, humor, dan adat istiadat di lingkungan baru (Thurber \& Walton, 2012). Hal tersebut juga dirasakan oleh mahasiswa perantau pada saat memasuki lingkungan baru. Kebahagiaan pada mahasiswa dapat diperoleh melalui pemenuhan 
Jurnal Psikologi Terapan dan Pendidikan

ISSN: $2715-2456$

Vol. 1, No. 1, Mei 2019, pp. 22-29

kebutuhan serta tugas perkembangannya. Mahasiswa yang bahagia adalah mahasiswa yang mampu menerima segala apa yang dimiliki dengan emosi yang positif. Selain itu, mahasiswa yang bahagia merupakan individu yang mampu menyesuaikan diri dengan dirinya sendiri serta lingkungan. Sehingga mahasiswa mampu menempatkan diri antara kebutuhan dengan harapan yang ada. Mahasiswa sebagai individu dewasa dini berada pada masa transisi dari masa remaja dan dewasa. Pada masa transisi ini mahasiswa dihadapkan oleh banyak perubahan yang dapat mengganggu upaya untuk mendapatkan kebahagiaan. Oleh sebab itu, mahasiswa harus mampu menyesuaikan diri terhadap segala perubahan di lingkungan. Individu yang mampu menyesuaikan diri dan mampu berinteraksi dengan baik pada akhirnya 7 mempengaruhi kebahagiaan pada masa dewasa dini (Izzaty, dkk; 2008)

Untuk mendapatkan suatu perasaan yang bahagia, tak jarang individu melakukan berbagai cara. Seligman (2005) menjelaskan bahwa pada kenyataannya individu menginginkan emosi positif, namun sering memilih jalan pintas imajiner yang tak terhingga banyaknya untuk merasa bahagia, seperti melalui narkotika, cokelat, seks tanpa cinta, berbelanja, masturbasi, dan televisi. Kebahagiaan yang diperoleh dengan cara tersebut hanya bersifat sementara, sehingga tidak akan menimbulkan kebahagiaan yang seutuhnya. Kegiatan-kegiatan tersebut menimbulkan ketergantungan atau bahkan dapat menimbulkan depresi.

Kebahagiaan sebagai emosi positif yang didapat melalui jalan pintas akan mengurangi nilai kebahagiaan itu sendiri. Jalan pintas tersebut membuat individu menjadi pribadi yang lain. Seperti yang diungkapkan oleh Seligman (2005) yaitu jika emosi positif yang terpisah dari penggunaan karakter akan mengarah pada kepalsuan, kehampaan, depresi dan sejalan dengan semakin menuanya manusia, ada kesadaran yang mengusik hati yaitu berupa kegelisahan sepanjang hayat manusia. Kebahagiaan yang semu tersebut dapat mengakibatkan kegelisahan bagi individu dalam menjalani kehidupan. Adanya pengalaman negatif juga dapat menimbulkan emosi yang negatif. Individu yang hidup dengan berusaha menjadi apa yang orang lain inginkan akan membuat individu tersebut memiliki konsep diri yang menyimpang. Akibatnya, pengalaman yang dialami individu yang tidak 8 selaras dengan konsep diri akan menimbulkan kecemasan (Farozin \& Fathiyah, 2004) Kurangnya kebahagiaan membuat individu terlihat murung dan seperti mengucilkan diri dari lingkungan sekitar. Ketika muram, individu menjadi gampang curiga, suka menyendiri, dan defensif berfokus pada kebutuhan diri sendiri, sedangkan mementingkan diri sendiri lebih merupakan karakteristik kesedihan daripada kebahagiaan (Seligman, 2005).

Kurangnya kebahagiaan yang dialami individu mengakibatkan kepribadian dan kehidupan sosial terganggu. Ketidakbahagiaan dapat menimbulkan hancurnya penyesuaian diri baik secara sosial maupun pribadi (Hurlock, 1997) Individu yang kurang bahagia memiliki penilaian yang negatif mengenai diri 
Jurnal Psikologi Terapan dan Pendidikan

ISSN: $2715-2456$

Vol. 1, No. 1, Mei 2019, pp. 22-29

maupun kepada orang yang ada di sekitarnya. Oleh sebab itu individu yang kurang bahagia memiliki penyesuaian diri yang kurang baik. Apabila hal tersebut terus terjadi, maka individu dapat mengalami kegagalan tugas perkembangan, khususnya pada aspek pribadi dan sosialnya.

Menurut Thurber dan Walton (2012), ketika memasuki lingkungan baru mahasiswa perantau akan merasa kurang memiliki kelompok familiar dan tidak jarang mahasiswa perantau akan merasakan stereotip yang kurang nyaman dari lingkungan baru. Perbedaan-perbedaan yang dihadapi oleh mahasiswa perantau dapat mengalami culture shock. Culture shock menggambarkan keadaan emosi negatif dan reaksi pasif dari individu salah satunya dtandai dengan perasaan homesick (Oberg, 2006). Berdasarkan hasil wawancara subjek mengatakan bahwa kebahagiaan mereka adalah saat berkumpul dengan keluarga. Homesickness merupakan perasaan distress yang disebabkan karena individu berada jauh dari rumah dan daerah asalnya (Thurber \& Walton, 2012). Indikator tersebut berlawanan dengan tanda-tanda kebahagiaan. Menurut Baumgardener dan Crothers (2010), kebahagiaan merujuk pada tingginya kepuasan hidup dan afek positif, serta rendahnya afek negatif.

Setiap individu memiliki kebahagiaan yang berbeda dengan individu lainnya. Hal itu dikarenakan kebahagiaan ditentukan oleh penilaian subjektif dari masing-masing individu (Myers \& Diener, 1995). Hal ini terlihat pada hasil wawancara tiap subjek yang berbeda-beda pandangan tentang makna kebahagiaan menurut masing-masing subjek.

Walaupun penelitian mengenai kebahagiaan sudah banyak tetapi kebahagiaan pada mahasiswa perantau masih jarang diteliti, padahal kompleksitas masalah kehidupan yang mereka hadapi mempengaruhi kebahagiaan yang mereka rasakan. Paparan hasil penelitian, pendapat para ahli, hasil wawancara dengan beberapa informan mahasiswa perantau, dan masih minimnya penelitian mengenai kebahagiaan pada mahasiswa perantau mendorong peneliti untuk mengkaji lebih dalam mengenai gambaran kebahagiaan pada mahasiswa perantau. Penelitian ini diharapkan dapat bermanfaat bagi keilmuan psikologi positif, khususnya mengenai kebahagiaan dan dapat memberikan informasi mengenai gambaran kebahagiaan dan faktor-faktor yang mempengaruhi kebahagiaan pada mahasiswa perantau yang dapat dijadikan sebagai bahan pertimbangan bagi pihak-pihak yang berkepentingan dalam membuat program untuk meningkatkan kenyamanan dan keberhasilan para mahasiswa perantau.

Tujuan penelitian ini adalah untuk melihat gambaran kebahagiaan pada mahasiswa perantau dengan mengetahui faktor-faktor yang mempengaruhi kebahagiaan pada pada mahasiswa perantau.

\section{METODE PENELITIAN}

Penelitian ini merupakan penelitian kualitatif dimana peneliti berperan membangun gambaran yang komplek dan menyeluruh, menganalisis kata-kata, sampai dengan melaporkan secara detail mengenai 
Jurnal Psikologi Terapan dan Pendidikan

ISSN: 2715-2456

Vol. 1, No. 1, Mei 2019, pp. 22-29

pandangan subjek, dan melakukan penelitian dalam setting yang alami. Metode dalam penelitian ini adalah Constructive Realism. Pengumpulan data menggunakan kuisoner terbuka dan FGD (Forum Grup Discussion). Kemudian data penelitian dianalisis dengan memadukan hasil kategorisasi data text.. Variabel yang diteliti adalah kebahagiaan pada mahasiswa perantau yang meliputi aspek-aspek kebahagiaan. Selain itu, penelitian ini juga meneliti faktor-faktor yang mempengaruhi kebahagiaan pada mahasiswa perantau. Penelitian ini terdiridari 20 subjek laki-laki dan 40 subjek perempuan Karakteristik subyek dalam penelitian ini adalah: a) Mahasiswa Perantau, b) Berusia 20-30 tahun, c) Bertempat tinggal di kota Yogyakarta. Langkah dalam pengambilan data dalam penelitian ini antara lain 1) Mengorganisasi data; yaitu membaca berulang kali data yang ada, 2) Membuatkategori, menentukantema, danpola, 3) Menguji hipotesis yang munculdengan menggunakan data yang ada, 4) Mencari eksplanasi alternatif data; yaitu peneliti mampu memberikan keterangan yang masuk akal terhadap data yang ada dan mampu menerangkan data tersebut berdasarkan hubungan pada logika makna yang terkandung dalam data tersebut, 5) Penulisan laporan; Teknik analisis yang digunakan dalam penelitian ini adalah analisis isi (content analysis) terhadap katakata, arti atau makna, gambar, symbol, atau tema-tema yang dikomunikasikan oleh hasil wawancara dengan subjek penelitian.

\section{HASIL}

Berdasarkan jawaban yang diberikan responden terhadap pertanyaan Di dalam kehidupan seharihari, apa saja yang membuat mahasiswa perantau bahagia diperoleh tiga kategorisasi antara lain relasi positif $65,36 \%$ bersyukur sebesar 28,10\%, dan kesehatan 6,54\% Hasil tersebut menunjukan bahwa pada gambaran makna kebahagiaan mahasiswa perantau adalah ketika individu memiliki relasi positif, bersyukur terhadap apa yang dimiliki, dan kesehatan.

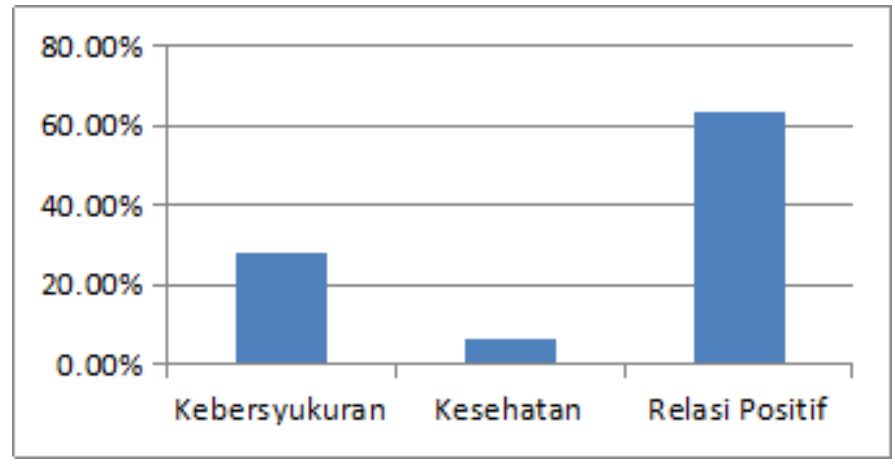

Gambar. 1 Sumber Kebahagiaan Mahasiswa Perantau 
Jurnal Psikologi Terapan dan Pendidikan

ISSN: $2715-2456$

Vol. 1, No. 1, Mei 2019, pp. 22-29

\section{PEMBAHASAN}

Hal ini didukung dengan hasil FGD dengan 4 mahasiswa perantau, subjek A mengatakan bahwa "saya sebagai mahasiswa perantau bahagia apabila saya sehat, karena ketika kita sehat itu mudah untuk melakukan aktivitas. Kedua adalah ketika saya bersyukur, karena dengan bersyukur apapun yang dilakukan itu menjadi enak, rukun dalam arti rukun dengan keluarga maupun orang disekitar" kemudian subjek B mengatakan bahwa "saya sebagai mahasiswa perantau bahagia ketika saya dapat bersyukur, walaupun misal saya hanya memiliki materi yang sedikit, tetapi ketika saya merasa itu cukup itu akan membuat saya bahagia. Dan juga Keluarga, ketika saya rukun dengan keluarga dan tidsk memiliki masalah yang berarti itu membuat saya bahagia. Serta ketika saya berfikir positif, ketika saya memiliki suatu masalah dan memiliki pikiran negatif, dengan berfikir positif saya merasa bahagia”. kemudian subjek C mengatakan bahwa "saya sebagai mahasiswa perantau apabila berkumpul keluarga, karena keluarga selalu bisa menerima apapun kejelekan yang saya miliki, dengan adanya kejadian negatif yang saya alami saya tetap berfikir positif karena menurut saya semua yang saya pikirkan dengan positif akan ada hikmahnya" dan subjek mahasiswa perantau D juga mengatakan bahwa "saya akan merasa bahagia apabila berkumpul dengan keluarga dan teman dekat yang satu pemikiran dengan saya”.

Hasil penelitian ini menunjukkan bahwa relasi positif dengan orang-orang yang signifikan dalam kehidupan memberi kontribusi bagi kebahagiaan mahasiswa perantau yang menjadi responden penelitian. Berdasarkan grafik diatas, relasi positif merupakan faktor yang paling dominan dalam memunculkan kebahagiaan mahasiswa perantau. Selanjutnya, yang menempati urutan kedua menunjukan sebagian besar responden melaporkan bahwa rasa bersyukur yang mendukung kebahagiaan yang dirasakan mahasiswa perantau dan faktor yang ketiga yaitu kesehatan, dimana kesehatan yang dirasakan mahasiswa perantau dapat mendukung kebahagiaan. Sejalan dengan kedua hasil tersebut, remaja akan berbagi kebahagiaan dengan sahabat dan keluarga (gambar 3). Hasil penelitian ini membuktikan pentingnya relasi positif dengan orang-orang yang signifikan dalam kehidupan untuk menciptakan kebahagiaan.

Respon jawaban untuk sub-kategori pada kuisioner terbuka juga menunjukkan bahwa orang-orang yang penting di dalam kehidupan individu, terutama keluarga dan teman, memberikan kontribusi bagi kebahagiaan yang dirasakan mahasiswa perantau. Hal ini memperkuat pandangan bahwa keluarga adalah agen sosialisasi yang memiliki kekuatan para mahasiswa perantau. Sejalan pula dengan Uchida et al (2004)

yang mengungkapkan bahwa kebahagiaan berakar dari dukungan dan rasa simpati yang saling menguntungkan.

Temuan dalam penelitian memperkuat penelitian tentang kebahagiaan pada orang-orang yang berasal dari daerah lain yang kemudian memutuskan merantau ke kota Yogyakarta, yang mana ditemukan 
Jurnal Psikologi Terapan dan Pendidikan

ISSN: $2715-2456$

Vol. 1, No. 1, Mei 2019, pp. 22-29

pada penelitian ini bahwa ketika mahasiswa berhubungan baik dengan keluarga, dan juga teman dekat dapat mendukung kebahagiaan. Hal ini diperkuat dengan hasil penelitian Al-Naggar, dkk. (2010) pada mahasiswa di Malaysia menunjukkan bahwa hubungan baik dengan teman dan keluarga merupakan salah satu sumber utama kebahagiaan mahasiswa.

Pada penelitian ini juga didapatkan hasil bahwa mahasiswa perantau bersyukur atas nikmat yang diberikan Allah walau sekecil apapun. Dan ditemukan pada penelitian ini bahwa kebersyukuran mendukung kebahagiaan para mahasiswa perantau. Hal ini diperkuat Penelitian Anggaraini, Andayani dan Karyanta (2013) yang menemukan bahwa individu yang bersyukur akan dengan mudah merasakan kebahagiaan. Kebersyukuran merupakan hal yang menyenangkan dan dihubungkan dengan emosi positif seperti kepuasan, kebanggaan, harapan dan juga kebahagiaan (Emmons \& McCullough, 2003). Kebersyukuran dalam penelitian ini diartikan sebagai kecenderungan umum untuk menyadari dan merespon dengan emosi bersyukur terhadap kebaikan orang lain dalam pengalaman positif dan apa yang diperoleh individu, dan menjadikan pikiran negatif menjadi suatu pembelajaran sehingga mahasiswa perantau berpikir positif. Mutia, Subandi dan Mulyati (2010) menyebutkan bahwa mampu berfikir positif merupakan salah satu gambaran dari individu yang bersyukur. Kebersyukuran dapat dimanifestasikan dalam perasaan-perasaan positif yang merupakan senang dan bahagia (Hambali, Meiza \& Fahmi, 2015). Dalam penelitian ini juga ditemukan hasil bahwa kesehatan mahasiswa para perantau ini mempengaruhi pemikiran dalam diri sehingga akan memunculkan perasaan bahagia. Karena ketika sehat mahasiswa perantau merasa akan mudah melakukan aktivitas apapun. Hal ini diperkuat oleh Carr (2004) yang mengatakan bahwa kebahagiaan memberikan berbagai dampak positif dalam segala aspek salah satunya memberikan kesempatan untuk memiliki umur yang lebih panjang.

\section{KESIMPULAN}

Penelitian ini menunjukkan bahwa makna kebahagiaan menurut mahasiswa perantau dipengaruhi oleh hubungan yang positif dengan keluarga maupun orang terdekat yaitu ketika mahasiswa perantau dapat berkumpul saat pulang ke rumah dan bertukar cerita bersama tentang hal-hal yang terjadi dalam kehidupan sehari-hari secara langsung maupun melalui alat komunikasi. Selain itu bersyukur juga mempengaruhi kebahagaiaan yaitu mahasiswa perantau menerima apa yang dimiliki saat ini dalam keadaan apapun sehingga dapat hidup nyaman dan tenang sehingga merasakan kebahagiaan. Serta kesehatan dapat mempengaruhi kebahagiaan yaitu ketika mahasiswa perantau sehat meskipun jauh dari keluarga maka akan memberikan kekuatan untuk melakukan segala aktivitas karena dengan sehat dapat melakukan segala hal yang diinginkan. 
Jurnal Psikologi Terapan dan Pendidikan

ISSN: $2715-2456$

Vol. 1, No. 1, Mei 2019, pp. 22-29

\section{DAFTAR PUSTAKA}

Al-Naggar, R. A., Al-Jashamy, K. A., Yun, L. W., Isa., Z. M., Alsaror, M. I., \& AlNaggar, A. G. A. (2010). Perceptions and opinion of happiness among university students in a malaysian university. ASEAN Journal of Psychiatry, 11(2) XX XX.

Baumgardener, S. R., \& Crothers, M. K. (2010). Positive psychology. New Jersey: Pearson Education, Inc.

Emmons, R. A., \& McCullough, M. E. (2003). Counting blessings versus burdens: An experimental investigation of gratitude and subjective wellbeing in daily life. Journal of Personality and Social Psychology, 84(2),377389.

Hambali, A., Meiza, A., \& Fahmi, I. (2015). Faktor-faktor yang berperan dalam kebersyukuran (gratitude) pada orangtua anak berkebutuhan khusus perspektif psikologi Islam. Psympathic Jurnal Ilmiah psikologi, 2(1), 94101.

Hurlock, E. B. (1999). Psikologi perkembangan: Suatu pendekatan sepanjang rentang kehidupan. Jakarta: Erlangga.

Mutia, E., Subandi., \& Mulyati, R. (2010). Terapi kognitif perilaku bersyukur untuk menurunkan depresi pada remaja. Jurnal intervensi psikologi, 2(1), 53-68.

Myers, D. G., \& Diener, E. (1995). Who is happy? Psychological Science, 6(1), 10-19.

Santrock, J. W. (2009). Life-Span development 12th ed. US: McGrawHill Internasional ed.

Thurber, C. A \& Walton, E. A. (2012). Homesickness and adjustment in university students. Journal of American College Health, 60 (5), 1-5.

Uchida, Y., Norasakkunkit, V., \& Kitayama, S. (2004). Cultural Construtions of happiness: Theory and empirical evidence. Journal of Happiness Studies, 5, 223-239. 